\title{
MULTILETRAMENTO E PRODUÇÃO DE IDENTIDADE NA SOCIEDADE CONTEMPORÂNEA: ANALISANDO ENUNCIADOS MULTIMODAIS
}

\author{
Lidnei Ventura ${ }^{1}$ \\ Thais Ehrhardt de Souza ${ }^{2}$ \\ Dulce Márcia Cruz ${ }^{3}$
}

\begin{abstract}
Resumo
O presente artigo investiga possíveis relações de determinação entre multiletramentos e produção de identidades na contemporaneidade. Parte-se do princípio de que tais identidades na modernidade tardia estão em constante mutação e são formadas e transformadas continuamente. Nessas condições, os processos de autorreferenciamento são marcados por narrativas do eu influenciadas por sistemas abstratos, dentre eles as mídias digitais. O argumento central é que as condições de autoria multimidiática permitidas pelas mídias digitais, ao mesmo tempo produzem identidades e são expressões delas, tanto no âmbito da cultura quanto das tecnologias utilizadas. Para exemplificar como as mídias digitais possibilitam manifestações de estilos de vidas e identidades, procede-se à análise de um vídeo do You Tube que reproduz uma coletânea da obra de Adoniran Barbosa, a partir do esquema interpretativo de Rojo (2013), que toma esse tipo de produção midiática como um enunciado multissemiótico e multimodal.

\footnotetext{
${ }^{1}$ Professor do Centro de Educação a Distância da Universidade do Estado de Santa Catarina, UDESC. Mestre em Educação e Cultura pela UDESC. Doutorando do Programa de Pós-graduação em Educação do Centro de Ciências da Educação, Universidade Federal de Santa Catarina, UFSC. Endereço: Rua Salvatina Feliciana dos Santos, 155. Itacorubi, Florianópolis, SC, BR, CEP: 88034-600. 1lrventura@gmail.com.

${ }^{2}$ Licenciada em Pedagogia pela Universidade do Estado de Santa Catarina, UDESC; Mestranda do Programa de Pós-graduação em Educação do Centro de Ciências da Educação, Universidade Federal de Santa Catarina, UFSC. Endereço: Rua Coronel Américo, 744. Barreiros, São José, SC, BR, CEP: 88117-310, thaisehrhardt@ hotmail.com.

${ }^{3}$ Professora do Departamento de Metodologia de Ensino e do Programa de Pós-graduação em Educação do Centro de Ciências da Educação, Universidade Federal de Santa Catarina, UFSC. Doutora em Engenharia de Produção, UFSC. Endereço: Rodovia Haroldo Soares Glavan, 4858, casa 3, Cacupé, Florianópolis, SC, BR, CEP: 88050-005. dulce.marcia@gmail.com.
} 
VENTURA, L.; SOUZA, T. E.; CRUZ, D. M.

Palavras-chave: Multiletramentos; Identidades; Autoria, Linguagens; Enunciados multimodais

\section{INTRODUÇÃO}

Enquanto vocêl Se esforça pra ser/Um sujeito normal/ E fazer tudo igual/ Eu do meu lado/ Aprendendo a ser louco/ Um maluco total/Na loucura real/Controlando/ A minha maluquez/ Misturada/ Com minha lucidez/Vou ficar/ Ficar com certeza/ Maluco beleza (Raul Seixas)

Os versos em epígrafe, de inspiração hippie e anarquista, que escandalizou a sociedade brasileira nos anos de 1970, já atormentada com os estilhaços do Movimento de Maio de 1968 pelo mundo, podem ser tomados como prenúncio das transformações que as identidades individuais e sociais sofreriam nas décadas seguintes em âmbito global, isto é, verdadeiras "metamorfoses ambulantes". De modo que "maluquez" e "lucidez" são lados de uma mesma moeda que travam uma batalha cotidiana na composição do mosaico identitário que interpela o sujeito contemporâneo.

O principal argumento deste artigo é que as condições de autoria multimidiática permitidas pelas mídias atuais, geradoras de diversos gêneros discursivos (enunciados multissemióticos), ao mesmo tempo em que produzem identidades, são expressões delas, tanto no âmbito da cultura quanto das tecnologias ${ }^{4}$, na medida em que põem em circulação estilos de vidas híbridos, metamórficos.

Nosso pressuposto é o de que as identidades contemporâneas são fluidas e estão em constante mutação e hibridização (GIDDENS, 1991; GIDDENS, 2002; HALL, 2001; HALL, 2013), sobretudo pelas condições histórico-sociais permitidas (impostas?) pelo capitalismo

\footnotetext{
${ }^{4}$ Como vai se demonstrar adiante, na análise de um enunciado multimodal, o DNA da identidade de várias mídias são (re)mixados na autoria, produção e circulação de textos multissemióticos na era das mídias.
} 
contemporâneo ou tardio (GIDDENS, 2002; HARVEY, 2009) e sua forma complexa de compressão espaço-temporal. E em meio a esse frenesi de destruição do espaço pelo tempo (HARVEY, 2009), a tecnologia, sobretudo a digital, tem papel preponderante na constituição do sujeito, exigindo dele, a cada átimo de segundo, novos processos de letramento(s), na medida em que precisa "habitar" (CERTEAU, 2014) a interdiscursividade proposta pelas mídias.

Neste sentido, partimos da hipótese de que as novas formas de comunicação social propiciadas pelas mídias podem provocar verdadeiras "diásporas culturais", adaptando-se aqui o conceito de Stuart Hall, à constante e em certa medida compulsória (re) adaptação, “(re) capacitação" (GIDDENS, 2002) e, porque não dizer, (re) patriamento cultural a que o sujeito contemporâneo se vê submetido diante dos impulsos e impactos tecnológicos provocados nos e pelos processos de interação social cotidianos. Sendo assim, diante dessas novas condições histórico-sociais, que têm pouco mais de 20 anos, ocorrem constantes e ininterruptos "deslocamentos de identidades", já que os sistemas de autorreferência e de constituição identitária dependem diretamente do modo como os sujeitos interagem com (e no) mundo social.

Por outro lado, os processos interdiscursivos postos no cotidiano atualmente têm caráter híbrido e multimodal, o que exige novas ferramentas de análise, haja vista que aquela centrada na escrita e na oralidade deixa escapar um elemento quase sempre presente nos enunciados mediados pelas mídias: a imagem em movimento.

Buscando testar novas ferramentas de estudo dos enunciados multimodais, esse artigo está estruturado de modo que se discute inicialmente a questão da identidade na contemporaneidade e os conceitos de (multi) letramento, multimodalidade e produção de identidade. A seguir, a partir das categorias "práticas de linguagem, situação de comunicação e gênero do discurso" propostas pelo Círculo de Bakhtin, conforme interpretação de Rojo (2013), analisamos um enunciado multimodal, em forma de vídeo disponível no YouTube. O objetivo da análise é identificar o caráter híbrido e multicultural proposto neste tipo de enunciação e suas possíveis consequências para a produção das identidades contemporâneas na medida em que há apropriação dos meios e formas de interação, informação e produção da comunicação na contemporaneidade. 


\section{A QUESTÃO DA PRODUÇÃO DA IDENTIDADE NA CONTEMPORANEIDADE DAS MÍDIAS}

A constituição da identidade, enquanto objeto de estudo, está longe de ser resolvida no debate acadêmico atual; mais longe ainda está o consenso entre os autores que se debruçam sobre a questão, sob seus múltiplos matizes. Então, para situar o leitor acerca do conceito de identidade que adotamos neste trabalho, começamos por tentar caracterizar os opostos do que seja a identidade humana, para depois chegar a um conceito afirmativo.

Partimos aqui do princípio de que a identidade humana não é algo essencial, que nasce com o sujeito e lhe acompanha do nascimento à morte; assim como não é algo natural da espécie, como uma fosse uma irresistível ontologia, outra forma de essencialismo ideal, que levado às últimas consequências, culmina na ideia de que há em algum lugar um "tipo ideal" de humanidade a ser atingido, seja pelo processo de evolução natural, por capricho do destino ou da deusa Fortuna, como admitiam os romanos. Ainda sobre a Fortuna, deusapatrona de uma concepção de mundo duramente estratificada, imperante ainda no seu tempo, Maquiavel reivindica a autoria dos feitos humanos quando diz que

um príncipe que se fia inteiramente na Sorte [Fortuna] acabará mal se ela mudar. Creio, além disso, que o príncipe que moldar sua conduta ao espírito de seu tempo será bem-afortunado. Da mesma maneira, ele experimentará o infortúnio se em suas ações desconsiderar seu tempo. (2008, p. 230).

Do ponto de vista de uma perspectiva histórica e cultural, a identidade humana não pode ser concebida fora das relações sociais e dos câmbios materiais e simbólicos próprios de cada tempo. Na medida em que o sujeito se depara com as condições postas diante de si e, sobretudo, na relação com os outros, vai se constituindo psicológica e socialmente a partir de mil "artes de fazer" (CERTEAU, 2014) e outras mil práticas de produção e reprodução da vida. De modo que é na contingência do cotidiano que as identidades contemporâneas são

\footnotetext{
${ }^{5}$ Segundo Michel de Certeau, "Ele [o homem ordinário] inventa o cotidiano, graças as artes de fazer, astúcias sutis, táticas de resistência pelas quais ele altera os objetos e os códigos, reapropria-se do espaço e do uso a seu jeito". (2014, contra-capa).
} 
forjadas, pois como diz Certeau, "O cotidiano se inventa com mil maneiras de caça não autorizada" (2014, p. 38. Grifos do autor). Neste sentido, a cada instante o sujeito é interpelado por forças que lhe exigem câmbio identitários e novas "aparições", tal como uma metamorfose ambulante.

Um dos maiores estudiosos da questão da identidade no nosso tempo, Stuart Hall, nos dá uma boa ideia da mobilidade adquirida pelas identidades na modernidade tardia:

\begin{abstract}
O sujeito, previamente vivido como tendo uma identidade unificada e estável, está se tornando fragmentado; composto não de uma única, mas de várias identidades, algumas vezes contraditórias ou não-resolvidas. Correspondentemente, as identidades, que compunham as paisagens sociais "lá fora" e que asseguravam nossa conformidade subjetiva com as "necessidades" objetivas da cultura, estão entrando em colapso, como resultado de mudanças estruturais e institucionais. O próprio processo de identificação, através do qual nos projetamos em nossas identidades culturais, tornou-se mais provisório, variável e problemático. (2001, p. 11).
\end{abstract}

Essa fluidez da identidade é, por um lado, auspiciosa, no sentido de que se quebram as amarras da identidade canonizada tradicional, que tende a condicionar o sujeito ao idêntico, ao mesmo, ao longo de toda sua existência. Essa noção é altamente problemática para aceitação das diferenças, o que no fim das contas gera toda sorte de ondas de discriminação e racismo. Por outro lado, essa concepção de identidade como "celebração móvel”, "formada e transformada continuamente" (HALL, 2001, p. 12), pode gerar insegurança e medo justamente por solapar a "sólida" base tradicional, na qual a noção romântica de um percurso de vida estava mais claro e estruturado. Ainda segundo Hall,

\footnotetext{
se sentimos que temos uma identidade unificada desde o nascimento até a morte é apenas porque construímos uma cômoda estória sobre nós mesmos ou uma confortadora "narrativa do eu". A identidade plenamente identificada, completa, segura e coerente é uma fantasia. (HALL, 2001, p. 15).
}

Sobre questões de identidade, serve aqui a surrada metáfora de Marx dizendo que tudo que é sólido se desmancha no ar, de tal forma que seria melhor se falar atualmente mais em processos de identificação do que de identidade, haja vista sua essência cambiante.

Outra passagem de Hall muito importante de se retomar devido a sua importância no quadro geral deste artigo que se refere à interpelação permanente a que estamos sujeitos em 
VENTURA, L.; SOUZA, T. E.; CRUZ, D. M.

meio aos fluxos materiais e simbólicos, que Certeau (2014, p. 47) chama ironicamente de epifanias mercadológicas. De acordo com Hall,

à medida em que sistemas de significação e representação cultural se multiplicam, somos confrontados por uma multiplicidade desconcertante e cambiante de identidades possíveis, com cada uma das quais poderíamos nos identificar - ao menos temporariamente. (2001, p. 12).

Podemos perceber uma ligação íntima entre a produção de identidades e os sistemas de significação e representação cultural no capitalismo tardio. Isso nos leva a considerar que a apropriação dos sistemas simbólico-culturais postos no cotidiano contemporâneo podem provocar ou fazer emergir múltiplas identidades, ainda que instáveis, arriscadas, móveis. O que nos leva também a considerar que os processos de multiletramentos postos na sociedade contemporânea, com seus enunciados cada vez mais multimodais, fazem parte de um amplo e complexo sistema simbólico-cultural de fundamental importância na constituição de processos de autorreferenciamento e identificação individuais e coletivos. Relembrando Giddens, a experiência canalizada pelos meios de comunicação enquadra-se nos sistemas especializados da modernidade e intensifica mecanismos de "desencaixe" ou "descolamento", o que provoca uma "imensa aceleração no distanciamento entre tempo e espaço" (2002, p. 24), levando a uma necessária revisão identitária, que inclui "recapacitações" (idem, p. 14) em ciclos cada vez mais curtos, levando os sujeitos contemporâneos a uma contínua busca por novos "sentidos do eu" ou novos sentidos de identidade.

Adaptando-se esses conceitos de Giddens e Hall, podemos levantar a hipótese que os processos de multiletramentos também são mecanismos de compressão tempo-espaço, que exigem dos sujeitos, em distintas instâncias e momentos públicos ou privados, o constante revolucionar de sua condição identitária, afim de que não sejam segregados das experiências cotidianas, cada vez mais mediadas pelas mídias.

Para embasar teoricamente essa hipótese, faremos no item seguinte uma síntese da discussão ainda em aberto sobre o conceito de letramento, buscando aprofundar a ideia de que processos de (multi) letramentos estão indissociavelmente ligados à constituição da identidade na alta modernidade a partir da mediação das mídias, que traz no seu bojo um vasto arsenal de enunciados multimodais. 


\section{MULTILETRAMENTO E MULTIMODALIDADE NA ERA DAS MÍDIAS}

Uma palavra que caracteriza bem as disposições da modernidade tardia, segundo David Harvey (2009) é flexibilidade. Para o autor, essa é uma espécie de palavra-arcano, com a qual procura distinguir os fundamentos do capitalismo clássico do modelo de produção flexível ${ }^{6}$ que, a partir da década de 1970 pôs em curso uma nova rodada de "compressão espaço-temporal" na experiência humana, alargando as fronteiras de atuação dos mercados e acelerando o "tempo de giro" da produção e da vida contemporânea em âmbito global. Essa observação parece teórica à primeira vista, mas quantas vezes ouvimos ou nos pegamos falando: “Puxa, já é natal!?” ou "Já estamos no fim do ano, esse passou rápido!” ou dizendo coisas semelhantes para nos referir a quanto a vida anda agitada e passando rápido demais, lembrando a canção Roda-viva, de Chico Buarque (Roda mundo/ roda gigante; Roda moinho/roda pião; O tempo rodou num instante/nas rodas do meu coração).

Essa crescente volatilidade da vida tem levado de rodo, além do nosso precioso tempo, também nossos valores, verdades e crenças. Mas, sobretudo, no torvelinho da flexibilidade atual, as identidades contemporâneas têm sido verdadeiramente atropeladas por um fluxo avassalador de informações, tecnologias, contrainformações, produtos, serviços e, principalmente, tragédias sociais e climáticas que obrigam os sujeitos a uma constante procura por novos "sentidos de identidade", cada dia mais provisórios, altamente problemáticos e, em larga medida, marcados por novos letramentos que, como diz Lemke, "produzem uma chave entre o eu e a sociedade" (2010, p. 456), transformando e sendo transformados cotidianamente.

Lemke afirma ainda que "os letramentos são transformados na dinâmica desses sistemas de auto-organização mais amplos [ecossociais] e nós, nossas percepções humanas, identidades e possibilidades - somos transformados juntamente com eles” (2010, p. 456).

\footnotetext{
6 “A acumulação flexível, como vou chamá-la, é marcada por um confronto direto com a rigidez do fordismo. Ela se apoia na flexibilidade dos processos de trabalho, dos mercados de trabalho, dos produtos e padrões de consumo." (HARVEY, 2009, p.140)
} 
Além dele, outros autores ligados aos estudos do letramento, ou mais precisamente aos Novos Estudos do Letramento (NLS), sob diversas perspectivas e campos teóricos, apontam para uma estreita relação entre os processos de letramento e produção de identidades, tais como James Paul Gee (1997) e Lankshear \& Knobel (2006). Brian Street, por exemplo, desenvolveu a concepção de "letramento ideológico", , a partir da qual identifica implicações mútuas entre processos de letramento e construção de identidades, afirmando

que as práticas de letramento são constitutivas da identidade e da pessoalidade (personhood). O que quero dizer com isso é que, quaisquer que sejam as formas de leitura e escrita que aprendemos e usamos, elas são associadas a determinadas identidades e expectativas sociais acerca de modelos de comportamento e papéis a desempenhar (2006, p. 466).

Ao que tudo indica, vem da interpelação polifônica que assola o sujeito contemporâneo, proveniente dos mais variegados enunciados sociodiscursivos, o sentido plural adquirido pelo termo letramento. O "s" no final da palavra proposto por diversos autores, a partir da década de 1980, não é mera concordância nominal, mas uma questão conceitual importante. "Letramentos são legiões" como diz Jay Lemke (2010, p. 455), porque, são sempre múltiplos e ligados a estratégias de significação social. "Não podemos continuar pensando que exista apenas um 'letramento' ou que isso seja apenas o que as mentes individuais fazem quando confrontadas com um símbolo de cada vez" (LEMKE, 2010, p. 458). Em letramentos não há lugar para o uno, para a monomodalidade, para a unicidade; ao contrário, são tão diversos quanto as comunidades comunicativas envolvidas. E cada uma dessas comunidades são provocações, são questionamentos aos sujeitos quanto a sua identidade, quanto as suas razões de agir e responder ativamente aos "apelos" do mundo contemporâneo.

No caso da produção teórica sobre o assunto, no Brasil, desde Freire sabemos que os letramentos, enquanto leitura de mundo e do texto - palavramundo - têm o poder de formar e

\footnotetext{
${ }^{7}$ Brian Street (1984) divide o letramento em dois modelos: autônomo e ideológico. O modelo de letramento autônomo está baseado em uma visão de padronização e concebido de maneira independente das condições sociais, culturais e econômicas. Já o letramento ideológico considera os processos de letramento permeados pela cultura e em situações de uso social da escrita.
} 
transformar identidades, pois, no limiar, a autorreferência identitária é uma forma de estar no mundo, habitá-lo, e atuar com e sobre ele. Em um texto autobiográfico maravilhoso e poético que escreveu para o fechamento do Congresso Brasileiro de Leitura, na cidade de Campinas, em 1981, chamado "A importância do ato de Ler" ${ }^{8}$, Freire deixou bem claro que a leitura do mundo não se dá autonomamente, mas nas relações dos sujeitos com o mundo. A passagem abaixo é uma das mais famosas e citadas do autor, mas a repetimos aqui pela sua importância:

\begin{abstract}
Refiro-me a que a leitura do mundo precede sempre a leitura da palavra e a leitura desta implica a continuidade da leitura daquele. Na proposta a que me referi acima, este movimento do mundo à palavra e da palavra ao mundo está sempre presente. Movimento em que a palavra dita flui do mundo mesmo através da leitura que dele fazemos. De alguma maneira, porém, podemos ir mais longe e dizer que a leitura da palavra não é apenas precedida pela leitura do mundo mas por uma certa forma de "escrevê-lo" ou de "reescrevê-lo", quer dizer, de transformá-lo através de nossa prática consciente (1981, p. 13).
\end{abstract}

E parece que isso tem muito a ver com a autorreferência de que falamos antes, já que a produção da identidade é uma forma de "escrever", ou melhor, "reescrever" o mundo. É por essa e outras mil razões que Paulo Freire é um dos pioneiros na discussão internacional sobre a importância da temática da alfabetização e do letramento. Exemplo disso é que no levantamento bibliográfico sobre novos letramentos realizado por Lankshear \& Knobel, Freire é apresentado não só como um dos protagonistas, mas como uma das razões para que literacy passasse "ao primeiro plano de atenção e esforços educativos" (2006, p. 09, tradução nossa) nos Estados Unidos e em diversos outros países de língua inglesa, a partir da década de 1970.

Se desde os anos de 1980 os letramentos, ponderados em toda sua multiplicidade sociocultural, já eram considerados importantes para o empoderamento dos cidadãos, na era da escrita, essa condição se amplia e multiplica na era da autoria multimidiática (LEMKE, 2010).

\footnotetext{
${ }^{8}$ O título desse artigo de Freire deu nome ao livro homônimo publicado, ainda em 1981, pela Editora Cortez: Autores Associados.
} 
Ainda segundo Lemke, todo letramento é letramento multimidiático, pois não se pode construir significados com a língua de forma isolada:

\begin{abstract}
Além disso, todo letramento é letramento multimidiático: você nunca pode construir significado com a língua de forma isolada. É preciso que haja sempre uma realização visual ou vocal de signos linguísticos que também carrega significado não-linguístico (por ex.: tom da voz ou estilo da ortografia). Para funcionarem como signos, os signos devem ter alguma realidade material, mas toda forma material carrega, potencialmente, significados definidos por mais de um código. Toda semiótica é semiótica multimídia e todo letramento é letramento multimidiático. (2010, p. 456).
\end{abstract}

Apesar de os últimos textos de Brian Street terem reforçado a ideia de multimodalidade e de que há mais convergências do que divergências ${ }^{9}$ entre os Novos Estudos do Letramento e a perspectiva do New London Group ${ }^{10}$, é com esse segundo grupo que o prefixo multi incorporado aos estudos do letramento ganhou duas dimensões importantes: a do hibridismo cultural e identitário, que caracteriza a alta modernidade, e a profusão de mídias e meios multissemióticos que enunciam formas complexas de comunicação postos na era pós-escrita, em boa medida motivados pelas mídias. Sobre essas duas dimensões, Rojo (2012, p. 12) informa que o conceito de multiletramentos "aponta para dois tipos específicos e importantes de multiplicidade presentes em nossas sociedades, principalmente urbanas, na contemporaneidade: a multiplicidade cultural das populações e a multiplicidade semiótica de constituição dos textos por meio dos quais ela se informa e se comunica". E acrescenta:

\footnotetext{
${ }^{9}$ Sobre as "complementaridades" teóricas e de objetivos entre os NSL e Multimodalidade, ver Street (2012). O autor cita Krees e Street quando afirmam que "NLS e multimodalidade, nesse sentido, estão bem posicionados para explorar pontos fortes e fracos uns dos outros, para desenvolver uma conversa que facilita o crescimento de novos e mais poderosas ferramentas" (STREET, 2012, p. 13, tradução nossa). No original: "NLS and multi modality, in this sense, are well placed to explore each others strengths and weakness, to develop a conversation that facilitates new growth and more powerful tools".

${ }^{10} \mathrm{O}$ New London Group, como ficou conhecido o grupo de pesquisadores que se reuniu em 1996 na cidade de Nova Londres (Connecticut, EUA), em seu manifesto A pedagogy of Multiliteracies - Designing Social Futures, defendeu a idéia de que os novos letramentos estão presentes na sociedade contemporânea tanto a partir da multiplicidade cultural que a constitui, quanto dos modos multissemióticos advindos, sobretudo, das novas tecnologias de comunicação.
} 
No que se refere à multiplicidade de culturas, é preciso notar: como assinala Garcia Canclini (2008[1989]: 302-309), o que vivemos hoje à nossa volta são produções culturais letradas em efetiva circulação social, como um conjunto de textos híbridos de diferentes letramentos (vernaculares e dominantes), de diferentes campos (ditos “popular/de massa/erudito"), desde sempre híbridos, caracterizados por um processo de escolha pessoal e política e de hibridização de produções de diferentes "coleções". (ROJO, 2012, p. 13, grifos da autora).

No âmbito das multissemioses que caracterizam os enunciados mediados pelas mídias, é preciso se considerar que vivemos em uma era pós-gráfica ou, como diz Santaella (2005, p. 66), numa era pós-imagem hipermidiática ${ }^{11}$, quando os conteúdos linguísticos de qualquer mídia são transformados em uma linguagem numérica binária, podendo ser manipulados de diversas formas, em diferentes suportes, ampliando usos e possibilidades comunicativas. Gee \& Hayes em Language and Learning in the Digital Age (2011) reafirmam o potencial enunciativo adquirido pela linguagem humana na Era Digital da seguinte forma:

\begin{abstract}
As mídias digitais são um interessante híbrido da linguagem oral com a linguagem escrita. [Elas] acentuam os poderes da linguagem oral e escrita, do mesmo modo que a linguagem escrita acentuava os poderes da linguagem oral.

[...] A linguagem sempre foi multimodal (combinando palavras, imagens e sons), assim como são muitas mensagens produzidas hoje por meio das mídias digitais e outras mídias contemporâneas. Ainda assim, a multimodalidade é mais onipresente, diversa e importante hoje do que jamais o foi. (2011, p. 01, tradução livre da profa. Gilka Girardelo, em sala de aula, no Programa de Pós-graduação em Educação, UFSC).
\end{abstract}

Além de onipresente, a linguagem, na Era Digital, “está 'canibalizando' e 'regurgitando' todos os tipos de imagem, fotográficas ou não" (SANTAELLA, 2005, p. 29), movimento esse que ao mesmo tempo em que mescla e hibridiza textos e significados, faz o mesmo com as ferramentas e meios de consumos, circulação e produção comunicativa.

Rojo, entretanto, alerta para o fato de que os multiletramentos requerem novas ferramentas e novas práticas (2012, p. 21) que vão muito além da caneta e papel, herdadas da escrita impressa. A presença simultânea de imagens, áudios, vídeos, além da exigência do tratamento da imagem, edição, diagramação e sincronismo [audiovisual] pressupõem a

\footnotetext{
11 Segundo Santaella, "na hipermídia, o texto, o desenho, os gráficos, os diagramas, os mapas, as fotos, os vídeos, as imagens geradas computacionalmente, e o som e os ruídos mesclam-se em hiper-sintaxes híbridas e sem fronteiras definidas" (2005, p. 60).
} 
produção de novas e múltiplas identidades autorais. No tempo em que as gravadoras e estúdios detinham os meios de produção de "peças audiovisuais", era relativamente fácil garantir a autoria de músicas, vídeos e/ou videoclipes. Já na era digital e sua possibilidade de produção/reprodução/mixagem individual de sons e imagens - o que pode ser feito de forma cada vez mais intuitiva, inclusive, com um aparelho celular - a autoria torna-se efêmera, porque difusa e desde sempre híbrida.

Mas se estamos, então, diante de enunciados multimodais, onipresentes, como afirmaram Gee e Hayes (2011), é preciso encontrar novas ferramentas de análise para investigar esse fenômeno e buscar nexos entre a produção desses enunciados e as identidades contemporâneas. E é sobre essa questão que nos debruçaremos no próximo item, procedendo a análise de um enunciado multimodal, seguindo o diagrama proposto por Rojo (2013), a partir de uma leitura da autora fundamentada nas ideias do Círculo de Bakhtin.

\section{ANALISANDO UM ENUNCIADO MULTIMODAL}

Segundo Giddens, a alta modernidade é caracterizada pela "abertura" da vida social e pluralização dos "contextos" de atuação antes impossíveis nas configurações sociais tradicionais $^{12}$. Isso significa que são múltiplas e variadas as "opções" identitárias que interpelam o sujeito contemporâneo, principalmente no que se refere aos "estilos de vida", levando-o a optar por uma vasta coleção de prática e fazeres, que são sinais de autoidentificação e autorreferência. No limite, o estilo de vida é também uma narrativa do eu, que num mundo multifacetado, precisa se localizar e fazer escolhas.

E no âmbito do mosaico de coleções passíveis de influenciar a construção de identidades na modernidade tardia está a mídia em geral, mas em particular as mídias digitais, que põem nas mãos dos usuários um novo poder (empowerment), o da autoria multimidiática, ao permitir que sejam "produtores culturais sem sair de casa” (SANTAELLA, 2005, p. 60).

\footnotetext{
12 “O mundo moderno é um 'mundo em disparada': não só o ritmo da mudança social é muito mais rápido que em qualquer sistema anterior; também a amplitude e a profundidade com que ela afeta práticas sociais e modos de comportamento preexistente são maiores" (GIDDENS, 2002, p. 22, grifos do autor).
} 
Na era das mídias, surge o "lautor" ou "produsuário", um resultado da diluição das fronteiras entre a leitura e autoria, como menciona Rojo citando Chartier (2007), que vai além do campo da escrita para considerar as condições de produção de leitura-autoria e estendê-la ao campo das multissemioses disponíveis na comunicação digital. Atualmente, portando um celular, o sujeito antes consumidor midiático, torna-se também produtor midiático. É emblemático o caso do vídeo que ficou conhecido como "Taca-le pau Marcos”. Produzido como uma brincadeira de criança que narra de forma entusiasmada a descida de um amigo em um carrinho de rolemã numa estrada de terra do interior de Santa Catarina, o vídeo de 25 segundos viralizou ao ser publicado na internet, dando ao seu jovem autor um status de celebridade na mídia. Tal foi o sucesso do vídeo que foi utilizado como vinheta de chamada da programação da Fórmula 1, na Rede Globo de Televisão, em 2014. Esse é um exemplo de como as mídias têm se estabelecido como celeiro de produção de estilos de vida e de identidades.

Os mais variados selfies, individuais e coletivos, produtores de performances, caricaturas e "estilos", antes de serem tomados como exposição do narcisismo contemporâneo também podem ser vistos como manifestações de autorreferenciamento, assim como os perfis das redes sociais e canais eletrônicos de informação e comunicação. Mais do que consumidas, as mídias atuais - enquanto processo de "leitura" multimidiática e multissemióticas -, numa referência a Michel de Certeau (2014), são "habitadas" por seus usuários, no mais das vezes remixadas, bricoladas e pastichizadas por seus "inquilinos".

Como bem lembra Rojo (2013), o texto contemporâneo é multissemiótico ou multimodal, envolvendo linguagens e mídias que produzem e exigem novos multiletramentos, em que a leitura do texto verbal escrito, analógico, não pode dar conta da complexidade dos enunciados hipermidiatizados atuais. Sobre isso, a autora afirma:

\footnotetext{
Esses "novos escritos" obviamente dão lugar a novos gêneros discursivos, quase diariamente: chats, páginas, twits, posts, ezines, epulps, fanclips etc. E isso se dá porque hoje dispomos de novas tecnologias e ferramentas de "leitura-escrita", que, convocando novos letramentos, configuram os enunciados/textos em sua multissemiose ou em sua multiplicidade de modos de significar. (2013, p. 20).
}

Com isso, as condições atuais de autoria multimidiática põem em circulação estilos de vida híbridos, metamórficos, originados em mídias diversas. Podem durar tanto os décimos 
de segundos de fama quanto os 15 minutos profetizados por Andy Warhol, ainda que nos dias atuais, em que tudo se desmancha no ar em segundos, 15 minutos de fama possam ser considerados uma eternidade e render, tanto grandes oportunidades financeiras, quanto tragédias retumbantes.

Para exemplificar como as identidades dos sujeitos e das suas produções multimidiáticas e multissemióticas podem se impregnar mutuamente partimos da análise de Rojo (2013, p. 30), que propõe um diagrama analítico para enunciados multimodais (reproduzido na Fig. 1). Tal diagrama é baseado na leitura que a autora faz de categorias do Círculo de Bakhtin, cujo tripé está assentado em três pólos: práticas de linguagem, situação de comunicação e gênero do discurso. Na obra de Rojo, o diagrama é utilizado para análise de um videoclipe de Marcelo D2, chamado "Dor de Verdade" e serve como ferramenta para uma compreensão da complexidade dos diversos aspectos linguísticos que apresentam.

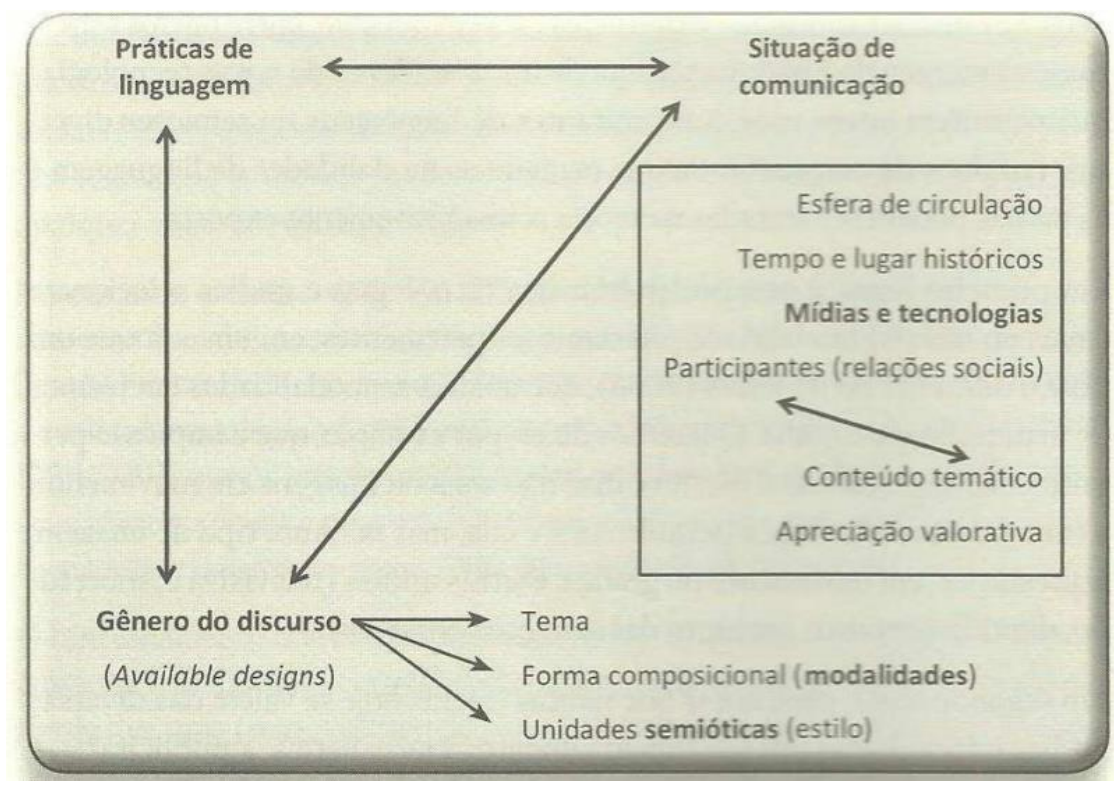

Figura 1: Elementos da teoria bakhtiniana dos gêneros discursivos. Fonte: Rojo (2013, p. 27)

Em função do escopo deste artigo, não vamos discutir todas as categorias bakhtinianas que fundamentam o trabalho da autora, mas frisaremos algumas ao longo da análise, acrescentando outra, heteroglossia, de grande importância para esse exercício de interpretação de enunciados multimodais, sobretudo aqueles caracterizados por imagens em movimento. Pode-se entender heteroglossia, em Bakhtin (ver CLARK e HOLQUIST, 1998), como a presença heterogênea de um enunciado em meio à multivocalidade discursiva social, 
ou seja, a singularidade da própria voz do autor no diálogo que aponta para a diversidade intralinguística e intracultural.

O vídeo que será analisado, com duração de 33 minutos, foi publicado no You Tube, em 27/10/2013, por um autor que se nomeia sinteticamente como Fred Hubner, sem nenhuma outra informação adicional. A descrição da postagem já se mostra complexa, dados os aspectos de hibridismo e multimodalidade que a compõem. Não há uma apresentação, nem justificativa, nem mesmo um comentário pessoal do autor da postagem. No endereço, temos visualmente duas imagens fixas, iguais, de um Adoniran Barbosa ${ }^{13}$ "típico" (sorridente, de gravata borboleta e chapéu de feltro) enquadrado em um porta-retratos cuja moldura muito se assemelha aos logotipos das emissoras de televisão (especialmente a Rede Globo e a Bandeirantes) como pode ser visto na Fig. 2. Ao ser acionado, o vídeo traz duas informações audiovisuais: graças a um efeito que simula visualmente o que ocorre com a superfície da água ao ser movida, a foto adquire movimento pela distorção sofrida pela imagem que vai sendo modificada enquanto acompanha a execução de seu conteúdo sonoro, como pode ser visto nas Fig. 3, 4 e 5. Em termos visuais, não há edição, a imagem consiste apenas no efeito que a distorce e, que, como um protetor de tela, inicia e reinicia quando seu ciclo termina, sem nenhuma relação de sincronismo com o som. Essa escolha que não é certamente apenas técnica nos remete a Lemke (2010) quando ressalta a necessidade de uma realização visual ou vocal de signos linguísticos, que também carrega um significado não-linguístico.

A fonte sonora é composta por um disco, lançado em forma de LP em 1984, pelo Estúdio Eldorado, que contém uma coletânea de algumas participações do cantor e compositor paulistano Adoniran Barbosa em programas de televisão e em entrevistas diversas. No início do vídeo, ouvimos uma descontraída entrevista feita pela cantora e

\footnotetext{
${ }^{13}$ João Rubinato, verdadeiro nome de Adoniran Barbosa, nasceu em Valinhos, São Paulo, em 6 de agosto 1910 e faleceu em 23 de novembro de 1982. Filhos de imigrantes italianos, Adoniran tirou do dia a dia da vida do paulistano suas inspirações para composições e personagens. Além de compositor de sambas memoráveis, tais como Trem das Onze, Saudosa Maloca, Iracema e tantos outros que foram imortalizados nas vozes de Clara Nunes e Elis Regina, também foi ator de televisão e cinema e locutor de rádio. O codinome, Poeta do Bixiga, representa bem o hibridismo cultural sintetizado por Adoniran ao longo de sua vida artística. (Fonte: Mariuzzo, 2010).
} 
apresentadora Elis Regina no programa "Fino da Bossa", exibido na TV Record, em 1965, que escolhemos como recorte para análise neste artigo. Na conversa, Elis pede detalhes sobre algumas músicas famosas do compositor, tais como Saudosa Maloca, As Mariposas e Trem das Onze, e canta com ele os trechos, improvisando, comentando e se divertindo com as "tiradas" bem humoradas de Adoniran.

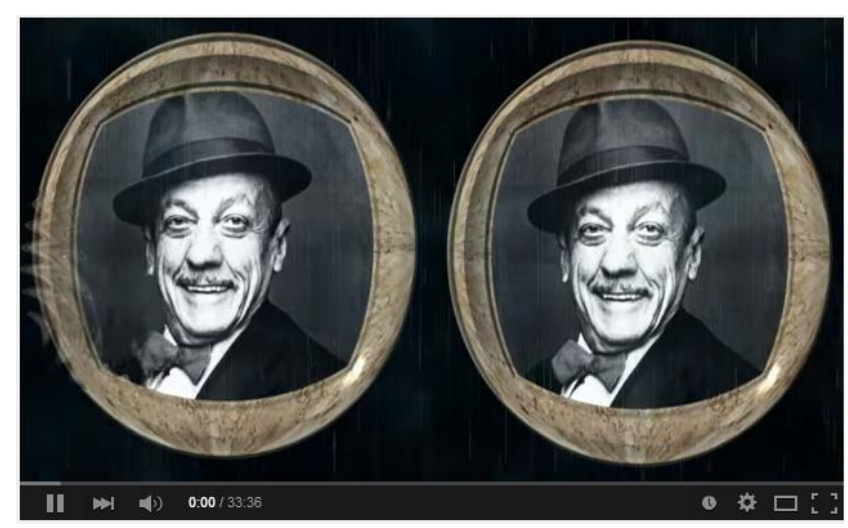

Figura 2: Imagem: print screen do vídeo no You Tube. Disponível em:

<https://www.youtube.com/watch?v=iDNt5bxvbXo> acesso em 27 março 2015

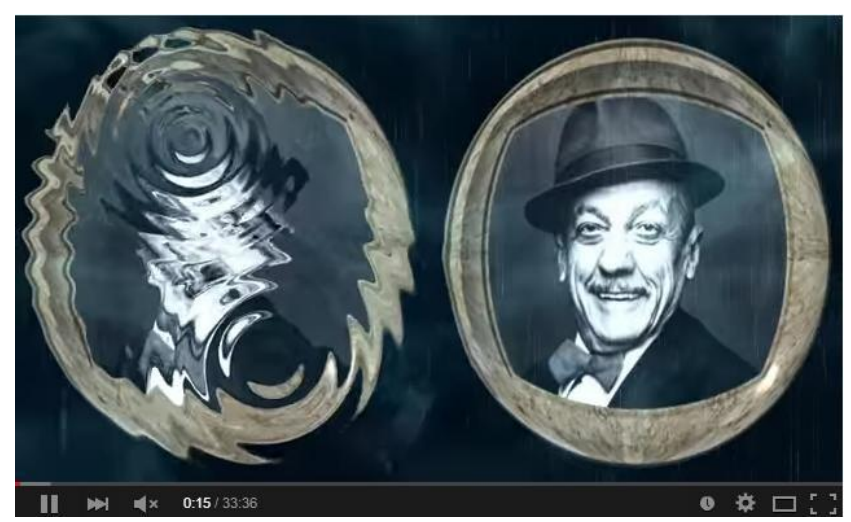

Figura 3: Imagem: print screen do vídeo no You Tube. Disponível em:

<https://www.youtube.com/watch?v=iDNt5bxvbXo > acesso em 27 março 2015

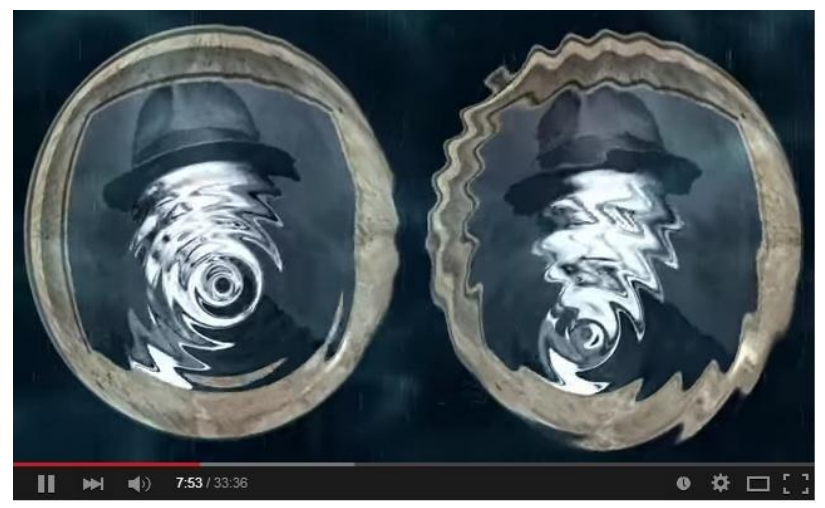


Figura 4: Imagem: print screen do vídeo no You Tube. Disponível em: <https://www.youtube.com/watch?v=iDNt5bxvbXo > acesso em 27 março 2015

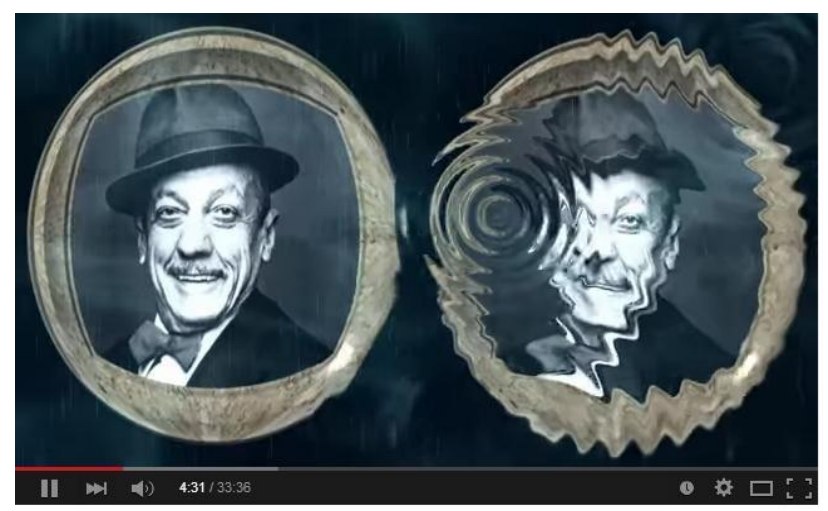

Figura 5: Imagem: print screen do vídeo no You Tube. Disponível em: <https://www.youtube.com/watch?v=iDNt5bxvbXo > Acesso em 27 março 2015

Do ponto de vista do enunciado discursivo, o vídeo que assistimos no You Tube com as canções e os diálogos entre os artistas, neste sentido polifônico, é também multivocal. Isso porque, abaixo da janela do vídeo, há uma identificação da data da sua publicação: Publicado em 27 de out de 2013. Abaixo, o título identifica seu conteúdo ao mesmo tempo em que chama atenção para sua importância: "Adoniran Barbosa com Elis Regina - documento inédito". Esta informação inicial e sua caracterização como publicação séria (documento) e excepcional (inédito) conota o objetivo de resgate de memória e de compartilhamento, típicos da cultura participativa.

Na linha de baixo, na tela inicial, lemos uma frase incompleta "Este é mais um Lp do meu marido. Pena que ele não possa viver comigo a emoção de escutar um trabalho tão bonito. Lembro-me de sua". Abaixo, um botão identifica que o texto pode ser lido em sua totalidade ao ser expandido através de um link: "Mostrar Mais".

Ao clicar no link, identificamos que se trata de um depoimento atribuído a Mathilde Barbosa, viúva de Adoniran, no qual comenta num tom emocionado e coloquial o que sentiu após ouvir o conteúdo da "fita" que continha o conteúdo que gerou o LP. A linguagem utilizada evidencia a informalidade de sua composição, não ficando claro se era um conteúdo oral reproduzido como texto escrito ou se foi produzido por escrito com a função de apresentar o LP, nem mesmo se ele consta do material informativo do disco propriamente dito, o que reforça a ideia de Gee \& Hayes (2011) de que a linguagem sempre foi multimodal (combinando palavras, imagens e sons) e que as mídias digitais permitem a criação de um 
híbrido de linguagem oral com a escrita. No site não há referência que identifique sua produção, mas, no final, o nome da viúva, local e data, remetem ao momento do lançamento do disco. Reproduzimos abaixo seu enunciado no formato com o qual está publicado no endereço do Youtube:

Publicado em 27 de out de 2013

ADONIRAN BARBOSA COM ELIS REGINA - DOCUMENTO INÉDITO -

Este é mais um Lp do meu marido. Pena que ele não possa viver comigo a emoção de escutar um trabalho tão bonito. Lembro-me de sua grande alegria quando viu prontos, em 1974 e 1975, os seus dois primeiros Lps gravados graças aos esforços de Pelão e, em 1980, quando Fernando Faro produziu o terceiro, com participação dele e vários artistas convidados.

Acabo de ouvir a fita deste comovente documento, produzido por Nogueira e Aluízio, lá mesmo na Rádio Eldorado, que era uma segunda casa de Adoniran. Ali ele fazia diariamente sua sesta, depois do almoço na cidade. Era o ponto onde marcava encontros, telefonava, resolvia shows. Depois de ouvir a fita, não posso deixar de escrever aqui: foi a coisa mais emocionante que escutei em minha vida. Mais do que um disco, vai ser um retraio (sic) do meu companheiro. Um retraio (sic) falado e cantado. Adoniran está inteiro nele, como esteve durante quarenta anos, na intimidade da nossa casa. Sua inteligência, suas piadas, alegrias e queixas, aquele jeito unicamente seu de comentar as coisas. Meu Deus, que trabalho bonito e verdadeiro!

Este disco foi feito sem artifícios de estúdio, arranjos, essas coisas que eu não entendo direito. Mas eu entendo muito de Adoniran Barbosa. E acho que o Lp do Estúdio Eldorado é inteiramente fiel à sua memória. Impossível ouvi-lo sem chorar de saudade, de emoção, de amor.

São Paulo, abril de 1984.

MATHILDE BARBOSA

(Disponível em: <https://www.youtube.com/watch?v=iDNt5bxvbXo > acesso em 27 março 2015)

Abaixo deste texto, o autor da postagem reproduz o que parece ser a ficha técnica do LP. Na lista detalhada, vemos que as faixas são compostas pelos trechos sonoros de programas da TV Record, TV Cultura, do Museu da Imagem e do Som de São Paulo, que reproduzem entrevistas, falas do compositor e de sua mulher, bem como músicas cantadas por ele e outros músicos, especialmente Elis Regina. Também constam informações sobre a equipe do Estúdio Eldorado, de São Paulo, que produziu a coletânea. No final, lemos que a "Categoria da postagem" é "Educação" e a "Licença para sua publicação" é "Padrão do Youtube". 
Essa descrição formal mostra não apenas o caráter multimodal dessa enunciação e sua característica de hibridez, mas a dificuldade de sua definição, em outras palavras, de sua identidade. Ao mesmo tempo em que mescla múltiplas linguagens, tornando-se multissemiótico, também se hibridiza a própria autoria/identidade do vídeo, pois, como afirma Rojo (2012), os multiletramentos requerem novas ferramentas e novas práticas. Ao mesmo tempo que possibilita a produção/reprodução/mixagem individual de sons e imagens, a autoria torna-se efêmera, difusa, híbrida pressupondo a produção de novas e múltiplas identidades autorais. Neste caso, levantamos a questão: de quem seria a autoria desse vídeo? De Fred Hubner, que fez a postagem? Da senhora Mathilde Barbosa, viúva do cantor e compositor, que faz referência ao lançamento do LP e cujas palavras acompanham a postagem? Qual seria a relação entre os dois? Dos músicos, cantores e compositores, que são os principais participantes do próprio audiovisual? $\mathrm{Ou}$, talvez, o que é mais provável: seria um vídeo produzido a muitas mãos?

Tecnicamente, a autoria do vídeo é de quem o postou no You Tube, entretanto, o que esse co-autor (lautor? produsuário?) fez, na verdade, foi digitalizar o som do LP, cuja origem tecnicamente é, desde sua gênese, polivocal, pois uma parte provém de fitas cassetes gravadas e remasterizadas pelo Estúdio Eldorado; e a outra provém dos trechos de programas de TV, dentre eles o que era conduzido por Elis Regina e Jair Rodrigues, que marcou o histórico encontro da cantora com Adoniran. Como lembra Rojo (2012), no tempo em que as gravadoras e estúdios detinham os meios de produção de "peças audiovisuais", era relativamente fácil garantir a autoria de músicas, vídeos e/ou videoclipes. No entanto, nesta situação, podemos dizer que o próprio LP já trazia um hibridismo, por ser a reprodução em áudio de trechos de alguns programas originalmente gravados como audiovisuais. Nesse caso, ouvimos e imaginamos o que não vemos, principalmente quando há referências sonoras a imagens que não constam no disco de áudio (e vale dizer, nem no vídeo postado, o que poderia ter sido uma opção do autor da postagem, ou seja, ilustrar o som com imagens referentes e afins, a exemplo de muitos videoclipes disponíveis no próprio You Tube).

Quando assistimos ao vídeo no You Tube (Fig. 2 a 5), vemos duas imagens de Adoniran (seria o retrato de Adoniran a que Mathilde se remete no texto do LP, reapropriado semiótica e metaforicamente por quem postou o vídeo?), talvez a foto da capa do LP, mas que não nos garante certeza por não trazer referência a sua autoria e seu momento de produção. 
VENTURA, L.; SOUZA, T. E.; CRUZ, D. M.

Como já descrevemos acima, as duas imagens vão se metamorfoseando ao longo da duração do vídeo, ocorrendo um acréscimo semiótico importante na percepção da obra, dando ideia de um movimento cênico do rosto do compositor. Essa necessidade da imagem como suporte ao áudio nos remete ao que afirma Lemke (2010), de que toda semiótica é multimídia e todo letramento é multimidiático.

Neste ponto, pode-se dizer que a autoria do vídeo é complexa e híbrida, assim como as multissemioses e identidades envolvidas nessa (re) produção. Para uma análise um pouco mais detalhada, escolhemos a primeira parte da Faixa A composta pelo rico encontro entre Adoniran Barbosa e Elis Regina, que desafia a interpretação, devido à complexidade que traz, tanto do ponto de vista das identidades ali presentes, quanto das multimídias utilizadas na autoria/produção/circulação deste enunciado.

Apresentamos, logo abaixo, nosso exercício de aplicação do diagrama de Rojo (Fig. 1) para esse enunciado híbrido e multirreferenciado, seguido de sua análise. 


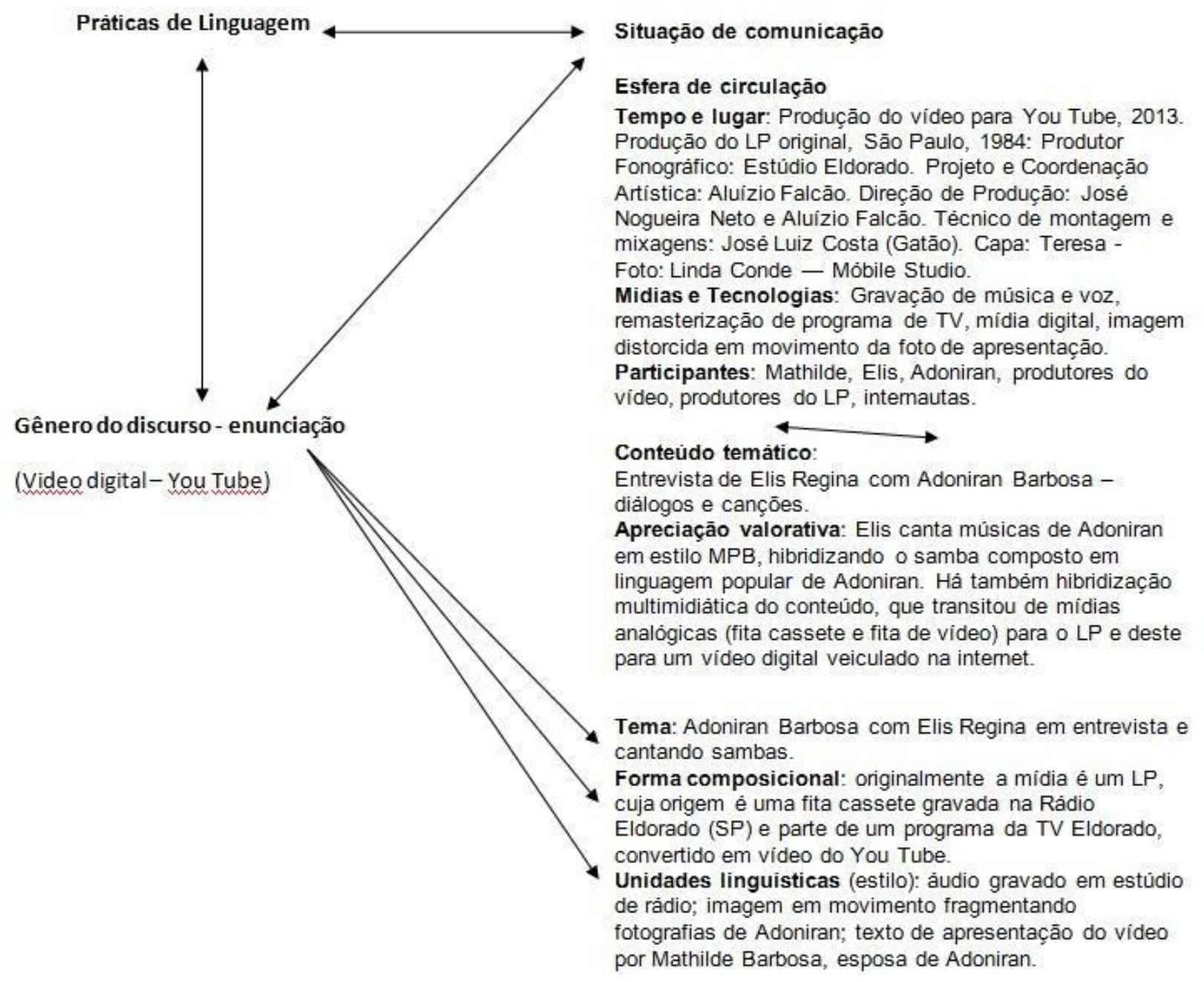

Figura 6: Diagrama elaborado a partir de Rojo (2013, p. 30)

$\mathrm{Na}$ esfera de circulação vemos que os tempos são múltiplos (LP em 1984; vídeo digital em 2013). Os produtores do disco também são múltiplos, já que, além da grande equipe necessária para sua realização, o que é típico da indústria cultural (rádio, TV, entrevistas), a publicação do vídeo permite a um usuário com acesso ao produto ressignificar a partir do acréscimo de informações que traz de várias fontes: a imagem do vídeo, o texto de Mathilde, as informações do disco. Da mesma maneira, as mídias são uma junção de várias fontes e tecnologias, e ações típicas das bricolagens. Por outro lado, "vemos" o disco, através do suporte visual como base do som, mas não temos acesso às imagens que fizeram parte da gravação original do programa de TV, Fino da Bossa. Essa mixagem, bricolagem e pastiche são um indício das práticas "habitadas" pelos usuários inquilinos, como afirma Michel de Certeau (2014), encarnados no papel de lautor ou produsuário, como lembra Rojo (2013). 
No recorte feito para nossa análise, a hibridização dialógica é outro fator de destaque, pois há interação entre o estilo "cult" de Elis e a fala popular de Adoniran, cuja marca é de subversão vernacular da Língua Portuguesa. Dessa mistura resulta o samba composto na linguagem popular do tradicional bairro de imigrantes italianos, o Bexiga, interpretado e interpelado pela variante da linguagem culta de Elis Regina. É possível também se destacar a heteroglossia presente no vídeo, pois Adoniran se serve de enunciados marcadamente ligados a sua cultura ítalo-brasileira, brincando e subvertendo palavras da língua portuguesa que mesclam o português e o italiano, dando origem a um terceiro vernáculo: o "adorianês".

\section{CONSIDERAÇÕES FINAIS}

A partir das discussões levantadas neste artigo, observamos o quanto a tecnologia, especialmente a digital, assume uma função de suma importância na sociedade capitalista, na contemporaneidade e na própria constituição do sujeito, exigindo novas habilidades em novos processos de letramentos.

Vimos que o sujeito contemporâneo não se compõe de apenas uma única identidade, como nas configurações sociais tradicionais, mas sim de várias, como é o caso do vídeo estudado. Neste sentido, as identidades contemporâneas estão em constante processo de mudança e hibridização, o que nos remete à questão da autoria propiciada pelas mídias, já que nesses processos interdiscursivos, que são de cunho híbrido e multimodal, sua análise requer novas ferramentas de interpretação.

Depois de apresentarmos a questão das identidades, modernidade tardia e o papel das mídias na sua constituição, apresentamos o diagrama analítico para enunciados multimodais que nos sugere a ideia de que as identidades dos sujeitos e suas produções multimidiáticas e multissemióticas podem impregnar-se de modo mútuo, na alta modernidade. Ao realizarmos a análise de um enunciado multimodal, optamos pela escolha de um vídeo do You Tube que nos instigou desde o início pelo seu caráter provocativo e que nos permitiu levantar questionamentos e hipóteses no que concernem às identidades nele presentes, bem como as multimídias utilizadas, a produção e a circulação deste enunciado. Mas a principal questão que permeou esta análise ainda fica sem resposta: afinal de quem é a autoria do vídeo? Da mesma maneira: qual(is) (são) a(s) identidade(s) entrevista(s) na análise dos componentes e 
linguagens de sua produção? Ao investigar os enunciados multimodais, vimos que a autoria necessariamente não se trata apenas de um ou dois autores, mas pode ser complexa e híbrida assim como reunir vários gêneros discursivos em uma mesma obra, num processo constante de letramentos multimidiáticos que desafiam nossas ferramentas de análise.

\title{
MULTILITERACIES AND PRODUCTION OF IDENTITY IN CONTEMPORARY SOCIETY: ANALYZING STATEMENTS MULTIMODAL
}

\begin{abstract}
This paper investigates the possible relations of determination between multiliteracies and identity production in contemporary times. It starts from the principle that the identities, as they occur in late modernity, are constantly changing and they are formed and continuously transformed. Under these conditions, the self-referencing processes are marked by narratives from "me" influenced by abstract systems, among which stands out the digital media. The central argument of this paper is that multimedia authoring conditions allowed by current digital media, generating various discursive genres, while producing identities, are expressions of them, both in the culture and technologies used. Methodologically, to exemplify how digital media may allow manifestations of lifestyles and identities, it proceeds to the analysis of a You Tube Video from the interpretive scheme of Rojo (2013) takes such multimedia production as a statement multi semiotic and multimodal, proceeds to the analysis of a YouTube video that depicts a compilation album of Adoniran Barbosa.
\end{abstract}

Keywords: Multiliteracies; Identities; Authorship; Languages; Analysis Multimodal

\section{MULTIALFABETIZACIÓN Y PRODUCCIÓN DE IDENTIDADES EN LA ÉPOCA CONTEMPORÂNEA: ANALISIS DE ENUNCIADOS MULTIMODALES}

\section{Resumen}


Este trabajo investiga las posibles relaciones de determinación entre la multialfabetización y producción de identidades en la época contemporánea. Se parte desde el principio de que las identidades, como ocurren en la modernidad tardía, están cambiando constantemente y son formadas y transformadas continuamente. En estas condiciones, los procesos de autorreferenciamiento están marcados por las narrativas del yo influenciados por los sistemas abstractos, entre las cuales se destacan las medias digitales. El argumento central de este artículo es que las condiciones de creación multimidiática permitidos por las medias, generadores de diversos géneros discursivos, al mismo tiempo en que producen identidades, son expresiones de ellas, tanto en el ámbito de la cultura cuanto de las tecnologías utilizadas. Para ilustrar cómo las medias digitales pueden permitir manifestaciones de identidad y estilos de vida, a partir del esquema interpretativo Rojo (2013) que toma ese tipo de producción multimidiática como un enunciado multisemiótico y multimodal, se procede al análisis de un video de YouTube que reproduce un álbum recopilatorio de la obra de Adoniran Barbosa.

Palabras Claves: Multialfabetización; Identidades; Autoría; Lenguajes; Análisis Multimodal

\section{AGRADECIMENTOS:}

Os autores agradecem, respectivamente: Ao Governo do Estado de Santa Catarina (UNIEDU Programas de Bolsas Universitárias de Santa Catarina) pelo apoio mediante Bolsa de Doutorado; Ao CNPq (Conselho Nacional de Desenvolvimento Científico e Tecnológico) pelo apoio financeiro mediante Bolsa Produtividade para esta Pesquisa.

\section{REFERÊNCIAS}

BARBOSA, Adoniran; REGINA, Elis. Documento inédito. Disponível em: https://www.youtube.com/watch?v=iDNt5bxvbXo. Acesso em: 10 Nov. 2014.

CLARK, K.; HOLQUIST, M. Mikhail Bakhtin. Tradução de J. Guinsburg. São Paulo: Perspectiva, 1998.

CERTEAU, Miguel. A invenção do cotidiano: artes de fazer. 21. Ed. Petrópolis, Rio de Janeiro: Vozes, 2014. 
FREIRE, Paulo. A importância do ato de ler: em três artigos que se completam. São Paulo: Autores Associados: Cortez, 1981.

GEE, James Paul. Foreword: a discourse approach to language and literacy. In: C. Lankshear (ed.) Changing Literacies. Buckingham: Open University Press, 1997.

GEE, J. P.; HAYES, E. Language and Learning in the digital age. London and New York: Routledge, 2011.

GIDDENS, Anthony. As consequências da modernidade. São Paulo: Editora UNESP, 1991. Modernidade e identidade. Rio de janeiro: Zahar, 2002.

HALL, Stuart. A Identidade Cultural na Pós-Modernidade. Rio de Janeiro: DP\&A, 2001. . Da diáspora: identidades e mediações culturais. Belo Horizonte: Editora UFMG, 2013.

HARVEY, David. Condição pós-moderna. 18. Ed. São Paulo: Loyola, 2009.

LANKSHEAR, C.; KNOBEL, M. New literacies everyday practicesand classroom learning. Maidenhead and New York: Open University Press, 2008.

LEMKE, Jay. Letramento metamidiático: transformando significados e mídias. Rev. Trabalhos em Linguística Aplicada, Campinas: Unicamp, vol. 49, n.2, Jul./Dec. 2010.

MAQUIAVEL, Nicolau. O príncipe. São Paulo: DPL, 2008.

MARIUZZO, Patricia. 100 anos de Adoniran: as mil facetas do compositor que foi a voz de São Paulo. Ciência e Cultura, São Paulo: UEC, vol.62, n.3. 2010. Disopnivel em: http://cienciaecultura.bvs.br/scielo.php?pid=S0009-67252010000300022\&script=sci_arttext. Acesso em: 14 Mai. 2015.

ROJO, Roxane. Gêneros discursivos do círculo de Bakhtin e multiletramentos. In: ROJO, Roxane. [org.]. Escol@ conectad@: os multiletramento e as tics. São Paulo: Parábola Editorial, 2013.

ROJO, Roxane; MOURA, Eduardo [orgs]. Multiletramentos na Escola. São Paulo: Parábola Editorial, 2012.

SANTELLA, Lucia. Por que as comunicações e as artes estão convergindo. São Paulo: Paulus, 2005.

STREET, Brian. Literacy in theory and practice. Cambridge: University Cambridge Press, 1984. 
VENTURA, L.; SOUZA, T. E.; CRUZ, D. M.

Literacy and Multimodality: STIS Lecture: Inter-Disciplinary Seminars O Laboratório SEMIOTEC, da FALE/UFMG Faculdade de Letras. Belo Horizonte, Brazil, 2012. Disponível em: http://arquivos.lingtec.org/stis/STIS-LectureLitandMMMarch2012.pdf Acesso em: 06 Mai. 2015

Perspectivas interculturais sobre o letramento. Rev. de Filologia e Linguística Portuguesa da Universidade de São Paulo, São Paulo: USP, n. 8. 2006. Disponivel em: http://www.revistas.usp.br/flp/article/view/59767. Acesso em: 14 Mai. 2015.

Data de recebimento: 29/03/2015

Data de aceite: 29/04/2015 